\title{
The use of information management tools as support to the product development process in a metal mechanical company
}

\author{
Fernanda Albuquerque Cunha, Jarina dos Passos Silva, Aline Capanema de Barros, Eduardo Romeiro Filho \\ Universidade Federal de Minas Gerais \\ e-mails: fernanda.ac@gmail.com; jarinapassos@yahoo.com; abarros2707@gmail.com; romeir@dep.ufmg.br
}

\begin{abstract}
In this paper, we present a case study developed in a Brazilian metal mechanical company on the application of computer systems as support for a product development process. In the first part, we present a literature review on themes such as product development, PLM and PDM (Product Lifecycle Management and Product Data Management) systems. In the case study, we describe the PDP - Product Development Process and the use of CAD/ CAE (Computer Aided Design and Engineering) systems in the company, as well as some problems observed. In the end, we propose some possible opportunities to PDP improvement using PDM systems.
\end{abstract}

Keywords: computer aided design, design methodology, product development process, metal mechanical sector.

\section{Introduction}

The increased competition has led companies to invest in technical and management solutions that can optimize the development of their products, reducing time, cost and gaining a significant competitive advantage. The support systems for product development available, such as the various $\mathrm{CAD} / \mathrm{CAE}$ (Computer Aided Engineering and Design), are seen by organizations, especially the metal-mechanical industry, as prerequisites for development (DANKWORT et al., 2004; FIGUEIREDO; ROMEIRO FILHO, 2011). In addition to the use of these tools, the variety and complexity of products developed together with the use of methods, such as Concurrent Engineering, in the metal-mechanical industry lead to a greater concern regarding the management of the development process (SHOUKE; ZHUOBIN; JIE, 2010; FERNANDES et al., 2005). In this context, the so-called PLM (Product Lifecycle Management) and PDM (Product Data Management) systems help to organize data, providing them at the right time and to the right people. They also work as a central data base and as support to the management of product development (MORRIS et al., 2004; WEBER; WERNER; DEUBEL, 2003).

This research starts with a literature review on the product development process and its supporting computational tools, being concluded with an exhibition of PLM and PDM systems, applications and their major suppliers. The paper goes on to present a case study in a large metal mechanical company that, by the end of the study, allowed the inferring of the difficulties faced by the company in its development process, the solutions that are being implemented and some propositions for situations that can be improved.

The use of CAD/CAE/CAM (including Computer Aided Manufacturing, which is not addressed in this article) in the metalworking industry is widespread, mainly due to the specific characteristics of the product manufactured. However, many companies see the application of PLM/ PDM systems to manage and store data or products "as a new business strategy in P\&D for companies" as recent (LI; WAN; XIONG, 2011, p. 1150). In this sense, it is important to identify the advantages of using these systems as a way to improve the management of product development in the industry.

As in the late 1980s and early 1990s, when systems of Enterprise Resource Planning (ERP) emerged, in the 2000s, the PLM implementation assumed considerable importance in most companies of information technology (IT) both in their activities and in their budgets. There are many parallels that can be drawn between some of the initial implementations of ERP and what happens today with the PLM: setting improper expectations of executive management, high costs of implementation, end-user frustration, armies of IT consultants, doubts regarding the investment returns. (HEWETT, 2010, p. 81).

Based on that, this article aims to describe and evaluate the implementation of computerized systems to support product development metal-mechanic in a metalmechanical company in Brazil, as well as to provide opportunities for the application of PLM and PDM systems to manage information on product development in the company. 


\section{Data and product's life cycle management}

Improving the product development process with the adoption of Concurrent Engineering has been one of the biggest challenges faced by companies. This means bringing products to market at a higher frequency in a shorter time (time-to-market) and with the quality required by customers (ROMEIRO FILHO et al., 2009). The use of support systems for management of products life cycle, known as PLM systems are of the utmost importance to organize and expedite the development of new products. According to CIMdata (2008), PLM is guided by three fundamental concepts: (1) maintaining the integrity of product, definition and related information throughout the life of the product, (2) keeping the information about the universal product secure and, and (3) ensure the maintenance and management of business processes used to create, manage, disseminate, share and use information.

\subsection{PLM e PDM}

The main difference between PLM and PDM involves the automation of the design process versus process reengineering. McEleney (2006) defines PLM as a strategy of process reengineering, designed to leverage design data and other technologies such as systems for enterprise resource planning (ERP). It is used to manage the life cycles of products, remake processes and improve production, with the productivity improvements coming from throughout the company, instead of coming from a single department or a specific process. The PDM, however, is seen as a tool that manages data from product design and engineering, to automate the development of products, increasing the efficiency within the existing processes. Within this concept, the PDM can be understood as part of PLM.

PLM systems include all features of PDM systems, $\mathrm{CAD} / \mathrm{CAE}$ and Project Management, as well as being linked to ERP systems, in other words, it is an integrated system that manages the information and the process of product development (GRIEVES, 2005). Today companies seek to meet their needs for product management by initiating the implementation of a PDM system. The most pressing need is to use 3D CAD (three-dimensional) and PDM solutions to improve the fundamental design of products and the engineering processes that support automated manufacturing. Paula et al. (2007) claim that the PDM is constituted as part of the functionality of the PLM concept, restricting itself to product specifications and the process itself. The functionalities of PDM systems can be divided into managing the process of product development and managing product information, and vary according to the manufacturer. These differ in price, scope of functionality and system architecture, but most use the same principles to manage information. They are important in all areas and steps of managing the life cycle of the product. According to Omokawa (1999), there is a set of essential features that characterize the system as a PDM. They can be divided into two groups: primary functions and support functions. The main features are listed below:

- DATA Vault - controls the creation and approval of documents and parts of the product, safety and access to data, relationships between data, check in and check out;

- Workflow - automates the processes by circulating, routing and controlling functions;

- Management of Product Structure - controls the list of materials, framework of parts and documents, management, and product configurations;

- Rating recovery - system of identification and classification of documents for quick search and retrieval of information;

- Project Management - functions of project planning and control, time control and resource allocation;

- Communication Notification - enables communication and notification between users and maintains interface with email. System;

- Data Transfer - mechanisms for data exchange between system users and between different applications;

- Services for viewing and comments (markup) - mechanisms for quick viewing of images and electronic information, without the need to run the source application;

- Administration - setup, customization, control of users and system administration.

In the industry, approximately $80 \%$ of companies still use a system that is manual and paper-based for controlling engineering modifications. The problems arising from this situation are many and directly affect the performance of the product development process. Outdated copies of drawings, slow circulation of documents, excess of paper, a high rate of rework and difficulty to obtain product information are common problems in most of these companies (ROZENFELD et al., 2006). The growing understanding regarding the functionality of PLM and PDM systems have led companies to large investments in this segment. According to CIMdata (2008), the global PLM market reached U.S. \$ 20.1 billion in 2006, demonstrating the role of PLM in improving the "business performance" of companies. The investments in PLM are expected to continue their ascent over time, increasing at a compound annual growth rate of about $8.5 \%$ to surpass the estimated $\$ 30$ billion by 2011 , to the tools of information, authorship and analysis of collaborative applications and management of product data. 


\section{The research performed}

The methodology for this research, especially in the case study, was based on social research methods (YIN, 2008). Besides the literature review, visits were made to the technical areas of Product Engineering, Rapid Prototyping and Scanning and to the Tooling Division. The sectors of stamping, welding and assembly, were also studied, together with other sectors of the company that had recognition visits. During the technical visits various people in the industry of Product Engineering were interviewed, ranging from designers to project managers, in order to understand the situation and delimitation of aspects related to product development. The visits were conducted primarily by direct observation of the activities of the sectors involved, interviews with various officials and analysis of relevant and non-confidential documents and files. Most of the interviews were open and semi-structured, being developed as new information and questions arose.

The project management area of the company was contacted and a design engineer was indicated to monitor the process. The visits were held on average once a week and often occupied the afternoon, and extended for a period of six months. Naturally, the structure and frequency of visits varied throughout the research: exploratory (more general) and observational of the work situation in its beginning and, in its end, focused on interviews with people related to the project.

A clear delineation of the problem observed - limited management of information related to the product development - emerged through observations and the first interviews. It was observed that the company had difficulties that were often not reported by employees, being perceived by researchers through interviews and comprehensive analysis of the industry structure. The performance of the visits and open interviews allowed a systemic view of the processes involved and gaps in relation to information of the project. From this, the research gained a well-defined focus, with the scope to acquire more elements on the management of information across the enterprise. The final phase of the case study dealt with the analysis of possible solutions to the problem, based on literature and observation of the actual situation and its many variables.

This case study was conducted in a large metalmechanical Brazilian company, which performs various processes of product development, often in partnership with its customers. The company offers services for CAD/ CAE/CAM, prototyping, development of definitive tooling, welding and assembly lines, and has physically separate units, each being responsible for parts of the production process or the manufacturing of different products. The prototype unit of the company has high-tech laboratories for testing products in the areas of metallurgy, acoustics, together with test centers of impact and mechanical testing. It also has a laboratory of system validation, micrograph and a verification center of emissions.

The company conducts the design and construction of tools, assembly and controlling devices. There are types of equipment that are made since the establishment of CAM programs for milling to $2 \mathrm{D}$ and $3 \mathrm{D}$ cutting of the tools components. There are also presses for conducting try-out of the tooling. The unit is divided into several cells; each produces one type of family of tools (the family concept is applied in steps or operations of the tooling). The Engineering of Product Development is responsible for projects, particularly in partnership with clients, conducting technical and economic feasibility studies; product development, assembly evaluation; modification of existing products (such as changing manufacturing materials); updates to sketches, analysis of technical standards and regulations.

\subsection{The product development system in the company}

The company has extensive know-how in product development, working in two ways: (1) the company shares the stages of product development with the client company, performing it in partnership (or co-design) or (2) it designs the manufacturing process of components already developed by the client company, including the manufacturing of tools for subsequent sale and/or supply of stamped parts. In general, the development begins with the contact made with the client company by the Sales Department (the commercial proposal, which is sent to the client, is developed jointly with other departments). When development refers only to the construction of the tooling, the Tooling Division assists the Sales Department in determining the hours required the development and manufacturing process of the piece. Thus, one can determine the cost of the product and tooling. In the case of co-design development, the participation of both the Development Engineering and the Tooling sector is required. This is due to the fact that it is necessary that the Engineering determines the hours and techniques necessary to define the piece, considering hours of project development, simulations, and tests on prototypes, among others. The Tooling Sector must inform the hours needed to manufacture tools and expenses with equipment (as well as the development via mathematics). If the company itself is responsible for the supply of parts, the sector of costs, along with other sectors mentioned, calculates the unit cost of part supplied. After preparing the budget for the client, and should they reach an agreement on the manufacturing, an NPN (Notification of New Products) is issued and various sectors in the company become involved in the product development, based on a reference number.

In the co-design development the first step is the definition of the product based on the received requirements. 
After the Development Engineering defines the product through simulations and tests on virtual and physical prototypes, the preparation of tooling begins. The Tooling initially performs simulations of process definition and subsequently the production tooling. Along with this development, there may be modeling or machining in expanded polystyrene models of parts of the tooling in order to enable the casting process of this component.

From the definition of the conceptual design with the specifications received from customers, it can be considered that the development is an overlap of the stages of detailed design and preparation for production. In this step, begin the tests of manufacture and assembly, simulations and prototypes, which fit into the detailed design and later the tooling design. At the same time, there are tests simulating the process of the tooling and definition of the manufacturing process of the product with number and type of stamping operations. After construction of the tooling, testes on the pilot batch are made for approval of the production of the requested batch.

The company produces spare parts, welded assemblies and complete systems. In the development, it acts not only as a supplier but as a partner in the product development. The degree of involvement varies according to both the client and the proposed product in two basic forms: (1) Construction of the tooling based on a project that has already been developed, in a traditional customer-supplier relationship and (2) participation in the development of the piece in co-design considering the specifications received. The co-design relationship occurs when the client selects the specialized suppliers for the development of the product and thus shares responsibility with the supplier, evaluating each phase of the process.

\subsection{Product Development Engineering}

The sector of Product Development Engineering (or simply Engineering), this research's focus, is responsible for the CAD/CAE of the company and the co-design partnerships with businesses customers. Its objective is the product itself and not the development of the production process. The sector cons ists of about twenty employees among designers and engineers, with division into cells, each responsible for a product or family of products. It is inserted in product development in the conceptual phase, the creation and/or validation of projects, and simulations prior to construction of any mock-up or physical prototype. The duties of the sector are: development of new products in co-design (studies of technical and economic feasibility, product design, assembly design, and component and project materials design); management of design changes; update of mathematical sketches; analysis of technical requirements and standards; and diverse simulations.
At the start of new projects, after the issue of NPN (New Product Notification), the project is transferred to Engineering. The designers and engineers of the sector participate in workshops with representatives of customers, in which the FMEA (Failure Mode and Effect Analysis) is made and some norms and standards of the client are presented to the supplier company. In situations where there is no co-design the supplier company must validate the design submitted by the customer in order to detect possible failures and prepare the design for subsequent simulations. The CAE stage is the phase of evaluation of ideas and consists of a series of simulations of the virtual prototype of the product. Simulations of the properties of the product and manufacturing process are made along with stamping simulations, which are responsibility of the Tooling unit. With the results of virtual simulations, a report is made and delivered to the CAD designers with the necessary modifications. Once approved in CAD, CAE and simulation in stamping, the project follows to prototyping in foam and/or testing with physical prototypes.

\subsection{The use of CAD/CAE systems in Development Engineering}

The CAD system is used in the first phase, which is of generation of ideas. At this stage, the company uses part of the knowledge gained in previous projects and specifications submitted in order to create possible solutions to meet customer requests. Sometimes changes or improvements to existing products can be requested. In this case, it is possible that the Development Engineering personnel receive the project of the product being modified, or even the physical piece that must be "scanned" (process in which the device covers the dimensional shape of the piece in 3D generating the contours of the product in CAD). The company has several types of CAD software to support the development, because each customer uses one or more specific kinds of software and often the client requires files to be uploaded in the standard of the company. In the preparation of the projects several parameterized operations that can be edited are made, which facilitates future modifications and corrections. However, when doing the conversion between software, these operations are often lost, making it necessary to redo them and correct the imperfections of transfers. There is a way to transfer files in IGES (Initial Graphics Exchange Specification) language in which there is loss of data and transfer errors that must be corrected by the designers after conversion.

After the brainstorming phase, the product follows to the simulations of manufacturing processes such as stamping. The simulations performed by the Tooling Engineering test the rupture sites, hardening or stretch of the material, i.e. define if the piece and tooling are possible 
to be manufactured. These results are sent to the CAD for any changes in points of product failure (later, simulations can be redone). The CAE is applied to locate the potential design problems. There is a pre-processor that imports the design of the CAD software and makes the preparation; a solver that performs the calculations until the solution, and a postprocessor to visualize the result through graphs. In most cases, the CAE studies are done after a prior definition of the product and are sources for possible design changes. The CAE simulations and virtual prototypes extensively reduce the real problems in products. These prototypes can replace some of the physical prototypes with savings in time and cost. This is because the virtual prototype can predict the incidence of failure and serve as a basis for product testing, functional testing and suitability for the design and assembly, besides allowing rapid changes as modifications in thickness, material or tolerances. Simulations of static and dynamic motion, such as torsion, tensile, fatigue, vibration, pulsation, temperature effects, durability testing, among others, are made.

The physical prototypes are used in tests of safety, endurance, fatigue etc. They are mainly used in products of high complexity, structural items and in tests of properties of materials still poorly understood (as in the case of new materials). Additionally, customers require prototypes prior to the final product for testing of interference and integration with other components, producing a pre-series of new products and using them in field trials. The physical prototypes used in field trials have their results compared with virtual ones so as to assess the proximity of the virtual solution, which reach more than $95 \%$, as quoted by the Engineering team. Overall, the use of CAD/CAE/CAM is intense in the company, and it is essential to maintain its position as supplier in the first level and the ability to co-design.

\subsection{Phases of project development}

When developing a product, the company must, besides follow the ISO standards, attend to the norms and standards specific to each client and also the local law (with greater attention to environmental and safety legislation). If involved in projects for export (which happens often) it will have to follow the law of the country to which the product is destined. A Book of notes of the development process is produced with every step, relevant documentation and all information and drawings of the products (the Book is pretty much standard for enterprise customers, with only minor changes to fit the needs of each). Most of the time, the phases described below occur simultaneously, because the steps are interdependent and need the results generated among themselves, besides the need for agility in the development process and the short term:
- Planning of product development - with definition of NPN, responsible team and schedule;

- Generation and evaluation of concepts - with the "idea generation" in CAD and evaluation of alternatives;

- Preliminary assessment of the project - analysis of technical, economic and financial feasibilities;

- Assembly design - defines the product structure and materials and all studies in FMEA and CAE of the product;

- Construction and testing of prototypes - components which can be purchased (as hoses, nozzles and seal rings in the case of systems for fuel tanks) are defined, together with other components produced using the CAM system;

- Validation/output of project - completed with the verification of the design and project information.

The model of the Book of products resembles the stages of product development, according to the model of stage gates presented by Rozenfeld et al. (2006). However, the stages are completely integrated as the phase of improvement of ideas and studies in CAE. In this case, the CAE identifies possible changes/improvements that can be made in the final product and allows, at the time of generation of the concept, changes in the product structure. During the development there are simulations that aim to test whether the tooling for stamping a product is or is not capable of being manufactured, that is, determine whether it is possible to stamp the product on a large scale. Prototypes are also produced before the construction of the tooling in order to test the impact resistance of the product, vibration, dynamic and actual stamping conditions (especially in case of complex products). After a certain product, with its final tolerances, material and dimensions, starts the process of construction and tooling.

\subsection{The management of data and information related to a product}

In the company, the cells of the Product Engineering team are separated by type of product developed. In the Tooling there is a team responsible for performing simulations of stamping. The tasks within the cell are divided between the team and there are people specifically responsible for CAD or CAE. There are also activities that are physically separated from the unit, with the prototyping industry. In the process, you can see the features of Concurrent Engineering as overlapping phases and cross-functional teams. The management of product data (such as simulations, CAD files that have been modified, drawings, etc.) is done individually by each designer. When there are extensive designs, as sets, or complex products, there is a need for more than one person working simultaneously on the same project. 
In these cases, there are situations, for example, in which more than one designer performs the same modification without the knowledge of the other members of the cell, which can cause changes in duplicate files. The database is individualized for each designer station, files are stored and separated by client name and the titles of the files are chosen by the performer. Each station has files of who operates, which are not saved in the network for security and confidentiality reasons.

There is a backup system, a server that can be accessed from all workstations and printers and can store project files. After working on the file, the designer can store it on the server. However, it is only compatible with files in the main CAD software used. In other cases, the files are managed by the designer, which holds all knowledge of revisions, modifications, or changes, and manages the files on his or her own. As a way to ensure the safety of files (since there have been cases of total loss of hard drives and stored information), a new workstation was acquired to be used as a backup system. In addition, CD recording are made each responsible for projects, after finalizing the development, which are stored in the "archive". The file storage both at the central backup unit and CDs does not follow any pattern (location and naming of files are defined by those creating them).

As for the final designs of product, they are managed by someone responsible for saving the final file project, which contains all the information and final rules. This latest version can only be changed by this person and this copy of the file and other user can only open it for reading. In general, the management of intermediate steps of the project is the responsibility of the designer, being filed by him or her, for consulting or to be used as base for future projects. After completing all steps of the project, the final design is also available to the Tooling, which will be responsible for building the tooling.

\section{Limitations generated by current data management}

The current data management in company has been identified as an item with several limitations. It was observed that the Engineering had not had the concern with his stage or even a perception that the current form of data management would be open to improvement, even with the various problems that were cited by industry personnel. There were cases when the designers left the company, making it virtually impossible to consult data on projects organized specifically by them. It is noticed that the filing of the outcome of intermediate stages of development is limited, since much of the information is stored only on the workstation of the responsible designer. Only projects approved by customers and ready for manufacturing tooling are archived on the backup system, to which only one person has access (practice started in late 2008).
The old projects or the ones that were interrupted are stored on CDs and the files are deleted from the computer where they were created. The time required for search and retrieval is typically long and files are not always found. Although the effects of these losses are difficult to measure, they imply (in practice) in the loss of part of the experience of simulations performed, the ideas already tested, the sequence of corrections already made. This situation is considered to be recurrent by many interviewed in the sector.

The naming of the files also proved to be a relevant point. The designers file the documents according to their understanding and personal needs. The only standard is to separate files per client, and there is no defined nomenclature for files or any indication for designers to use in order to have a better standardization and data management. This management creates an individualized way to name files and thus the recovery of old projects is slow, even if carried out by the person responsible for the file. There is also no standard for identifying the latest revision, which can create problems in sending to other sectors of the correct version. As an example, a case was described in which the design was sent to the Tooling in its intermediate version which created a loss of approximately 400 hours of work in machining.

Another issue to be addressed is the flow of information. Designers are responsible for sending the information and file for the sectors the follow. One worker reported cases when one sector claimed to have released the project, but the next said it was never received. Currently, there is no way to control that flow of information between sectors to know whether the employees actually sent or not the information, with the possibility of delays if such situations occur.

Regarding the revisions of drawings, copies are distributed to all related sectors, usually by electronic or physical copies (which are printed in the sectors of destination). This process is slow, since it is necessary to deliver to the Tooling and factory paper copies or send electronically to all sectors that can use the drawings. Sometimes, even before a revision has been fully disclosed, there is already a new one being made which lead to often working in outdated versions. Another aspect is related to more complex projects, with several people involved, because a designer can make a change without the knowledge of others and they work in the opposite direction, making changes similar or incompatible with each other.

These problems and limitations were reported by designers or observed during the study, despite the company's extensive experience in product development and widespread use of CAD/CAE, with the simultaneous application of different software. It was demonstrated that the management of design information is the main challenge of the company and source of conflicts and errors. The measurement of these problems, on the other hand, is a limit to the research because there is no record 
of losses occurred due to inappropriate use of CAD/ CAE. Naturally this gap comes from the limitations of the system management. Although perceived by many of the respondents, problems of information management are not logged in a way that allows their measurement. Still, it is believed that the research model used was appropriate for the understanding of the problem treated, generating subsidies for recommendations for improvement.

\section{A proposal for development process improvement}

The need to provide product information at the right time and for the right people is important to have an effective management of data, which can be done by PDM systems. In the Development Engineering sector, the PDM can provide process optimization, and make it safer, creating a single database that can eliminate (or reduce) the problems of duplicate files, lack of version control, loss of data, drawings and history of the projects, storing properly and reducing time for location of information. However, there is a great variety and diversity of systems of data management of the product on the market, which have a strong range of features. Nowadays, many companies use it in the development phase and not throughout the life cycle of the product (in this case, including prototyping and tooling).

As noted during the research, the company has limitations with regard to the management of information relating to products developed by Engineering. As already mentioned, the current system is flawed because the filing, search and project control is very sensitive and unreliable. The company works with a large number of clients and has a prominent position in product development in Brazil, and is one of the few to possess the necessary requirements for participation in co-design projects. Given these conditions, it becomes increasingly necessary that the company adopts a more effective way for controlling the designs and information.

The literature review indicates PDM systems and their functionality as a solution for improving the current data management. One of the perceived problems was exactly the information loss due to rotation of designers, who have control of the files and data and revisions, as there was no pattern of archiving of the projects. The PDM systems can eliminate the need to save files in the workstation itself or even CDs, making information more secure. Even discontinued projects can be kept on file, as well as CAE simulations, which currently are not archived (because they occupy too much memory).

Nowadays, there are problems in disseminating revisions of drawings, since the distribution of files is slow. In PDM, the designs can be viewed in real time, and users only have access to the latest revision. The electronic preview facilitates dissemination of revised drawings. In the central database, with the PDM solution, the files are saved in a standard nomenclature, to be set during its deployment.
This could facilitate the search and recovery of files from old projects.

In PDM systems, access to information is limited by user groups. Thus, each user profile has access to only certain information, keeping files secure and confidential. Changes may be made only by certain users and two people cannot change a file simultaneously, reducing possible rework. Furthermore, the system identifies who was responsible for the last change. Another important feature of PDM is that once the flow of information is deployed and set, it is not necessary for users to send files (via email or paper). The system itself controls the release of the drawings, because the flow is already provided. Or, when a drawing is done, it automatically goes to the subsequent sectors determined. The PDM can optimize the approval and introduction of new products, increasing the competitive potential of the company. Probably, the customers themselves would have a better vision for the company.

\subsection{The proposed implementation of a PDM system in the Tooling unit}

The company has a strong policy of investments in technology. The tooling has noted the need for efficient data management and has begun to implement a PDM solution. According to respondents in this sector, the selected software is the most widely used among the company's customers.

The implementation of PDM, as well as other data management software is quite complex and requires a broad restructuring work. It's a long job that needs to be done well so that there are really positive results in the future. The system provider, like other suppliers of this type of solution, monitors and shapes the product according to customer needs.

In the Tooling, a chain reaction is happening because this type of data management software will require a gradual update of the previously existing infrastructure of project management. Since the exchange of hardware (machines with high processing), software, servers, networking and also the upgrade and training of personnel - all this mobilization for the implementation of PDM, installed on a server to access all computers sector. It is a complex task and in the new system there is no more traffic between computers, only computer and server. Only in network infrastructure and cabling the expenses were approximately $\mathrm{R} \$ 150,000.00$. Regarding the hardware, these solutions require a very high processing capacity and for that 16 multicore processors were installed. A central server was installed, and another one for backup and thus there was gain in processing speed. Some CNC machines are older and are not able to support the size of the new 3D files. Gradually these machines need to be replaced (having in mind its lifetime). 
The implementation in the Tooling is to last for about a year and a half. About $60 \%$ of the deployment time of PDM focuses on defining the design of workflows, determination of inputs and outputs, standard nomenclature for the drawings and files, definition of user profiles, which have permission and type of access. The next step is the training of the users who will use the system, beginning with a 40-hour basic course for everyone. Later, more advanced training will be made according to the need of users. It was also pointed out the importance of the application of ISO standards for the implementation of PDM, since information flows and the inputs and outputs, as documented in ISO and very useful for system deployment, are required.

With the implementation of PDM, it is expected to reduce the use of paper drawings, since the project will be displayed on terminals available throughout the tooling sector, enabling $3 \mathrm{D}$ visualization. In offices, this will be done through the computers themselves. The system will also enable greater integration with the sectors of modeling and virtual simulation of machining, improving information management in a comprehensive way. Besides the implementation that has already started, there are a few studies for developing and creating new tools, also using PLM. The company is a pioneer in a work that seeks a way to automatically chain project schedules with the drawings and files to be worked on.

\section{Conclusions}

For this study, the development process of products in a company was investigated, particularly in regard to the management of information. It was noticed that despite this being a major player in the Brazilian market, there is still much to be done in order to make the management of data and information of product development more efficient. The creation of a proper filing system (including ideas not used and CAE simulation, for example) and a standard for file naming are examples of that. Although they seem marginal to product development, these issues, imply in difficulties throughout the process, including to subsequent phases, generating impacts in later stages of the production process (as in Tooling).

PDM systems show up as an efficient way of management of product information. The most comprehensive and integrated form of PDM/PLM, which is evaluated throughout the lifecycle of the product is especially well suited to the case analyzed, but presents itself as an opportunity for the future, in view of the difficulties encountered by the company in its current state. Therefore, it is recommended to gradually adopt a PDM system and then migrate to a PLM philosophy that more appropriate to the competitive landscape observed since the 2000s. Companies using PDM systems focus on data management features, as this is its most obvious application. The company studied realized the importance of using these systems and began the process of implementing a PDM system in the Tooling unit as a means of improving the processes in this area. The system will ensure the display of 3D design, integration with modelling and virtual simulation sectors for machining, and improve the management of information in general. The situation analysis of Product Engineering, focus of this study, indicates the need for improvement. However, there is still lack of perception of the problems generated by current data management. In this case, the application of a tool such as PDM presents itself as convenient to make those involved with the system in the company (engineers, designers, managers, etc.) progressively realize the advantages of their application and prepare for more sophisticated solutions such as those proposed by PLM.

It is noticed that the PDM system implemented in the Tooling can be extended to Engineering, which can generate large improvements in data management of the PDP of the company, solving problems discovered during the study. Thus, much of the structural adjustments would have been made and the system interface would be already known, reducing deployment time in Engineering, and enabling the integrating of areas in the company. The future deployment of the PLM and its extension to the Development Engineering will generate a competitive gain for the company, once it facilitates the partnership with clients, which is a key to the company researched. Furthermore, they can take the company to a leading position in the market and become a supplier with exceptional structure and higher know-how on product development.

\section{Acknowledgements}

The authors thank CAPES and CNPq for supporting this project.

\section{References}

CIMdata. Global Leader in PLM Consulting. PLM, 2008. Disponível em: <http://www.cimdata.com/plm.html>. Acesso em: 25 set. 2008.

DANKWORT, C. W. et al. Engineers' CAx education - It's not only CAD. CAD Computer Aided Design, v. 36, n. 14, p. 1439-1450, 2004. http://dx.doi.org/10.1016/j. cad.2004.02.011

FERNANDES, J. M. et al. Cross-functional teams and concurrent engineering: contributions to the development of product design through multidisciplinary integration using CAD systems. Product (IGDP), v. 3, p. 5-9, 2005.

FIGUEIREDO, A. C.; ROMEIRO FILHO, E. As Práticas de Sistemas CAD e sua Contribuição: um Survey na Indústria Metal-mecânica Mineira. Produção, v. 21, p. 1-11, 2011. http://dx.doi.org/10.1590/S0103-65132011005000024 
GRIEVES, M. Product Lifecycle Management: Driving the Next Generation of Lean Thinking. McGraw-Hill, 2005.

HEWETT, A. Product Lifecycle Management (PLM): Critical Issues and Challenges in Implementation. In: NAMBISAN, S. (Ed.). Annals of Information Systems. New York: Springer, 2010. vol. 5: Information Technology and Product Development.

LI, Y.; WAN, L.; XIONG, T. Product data model for PLM system. International Journal of Advanced Manufacturing Technology, v. 55, n. 9-12, p. 1149-1158, 2011. http://dx.doi.org/10.1007/s00170-010-3130-4

McELENEY, J. J. PDM vs. PLM: Determinando que solução é a melhor para você. SolidWorks Corporation, 2006.

MORRIS, H. et al. Information integration framework for product life-cycle management of diverse data. Journal of Computing and Information Science in Engineering, v. 4, n. 4, p. 352-357, 2004. http://dx.doi.org/10.1115/1.1818684

OMOKAWA, R. Utilização de sistemas PDM em ambientes de engenharia simultânea: o caso de uma implantação em uma montadora de veículos pesados. 1999. $169 \mathrm{f}$. Tese (Doutorado em Engenharia Mecânica)-Escola de Engenharia de São Carlos, Universidade de São Paulo, São Carlos, 1999.
PAULA, F. F. P. et al. Análise da Integração entre um Sistema de Gestão de Dados de Documentos e um Sistema de Gestão de Projetos Contexto da Gestão do Ciclo de Vida de Produtos (PLM). Produção On-line, dez. 2007. Edição Especial.

ROMEIRO FILHO, E. et al. Projeto do Produto. Rio de Janeiro: Elsevier Editora Ltda, 2009. v. 1, 374 p.

ROZENFELD, H. et al. Gestão de desenvolvimento de produtos: uma referência para a melhoria do processo. São Paulo: Saraiva, 2006.

SHOUKE, C.; ZHUOBIN, W.; JIE, L. Comprehensive evaluation for construction performance in concurrent engineering environment. International Journal of Project Management, v. 28, n. 7, p. 708-718, 2010. http://dx.doi. org/10.1016/j.ijproman.2009.11.004

WEBER, C.; WERNER, H.; DEUBEL, T. A different view on Product Data Management/Product Life-Cycle Management and its future potentials. Journal of Engineering Design, v. 14, n. 4, p. 447-464, 2003. http://dx.doi.org/10.1080/09 544820310001606876

YIN, R. K. (Ed.). Case Study Research: Design and Methods. 4th ed. (Applied Social Research Methods) Sage Publications, Inc., 2008. 